\title{
Possibilities of applying structural optimization in building structures computer-aided design systems
}

\author{
Andrey Vasilkin* \\ Moscow State University of Civil Engineering, Yaroslavskoye shosse 26, Moscow, 129337, Russia
}

\begin{abstract}
For computer-aided design solutions search, a computational tool, which will substantially facilitate designer's work, has been developed. Structural optimization method - genetic algorithm method is taken as a basis. To accelerate design solutions synthesis, computer-aided design system in the form of a developed computational tool is used. It automatically synthesizes a significant number of design solutions using formalized conditions of strength facility requirements. Then, user compares the solutions upon performance criterion and selects the best options. The article demonstrates possibility of genetic algorithm application for obtaining design solutions through the example of a structural coating plate. The advantage of this method is obviousness in solutions search, visualization of proposed structures and user's work with the system in dialog mode.
\end{abstract}

\section{Introduction}

Design stage is one of the most important stages in structure life cycle, since most functional and consumer characteristics are developed as well as reliable and durable operation of construction facility is ensured at it. An important requirement for facilities under construction is economic efficiency, consisting of several components [1,2].

Unlike strength requirements, definitely regulated by design standards, ensuring economic efficiency of the facility throughout all stages of its life cycle is a difficult task, because it is a function of several arguments: material cost, manufacturing cost, installation cost, operating cost. Only the first component correlates well with strength, the remaining cost parameters are more difficult to take into account, since they do not have a linear dependence on structure load-carrying capacity, but depend on a number of difficult-toformalize conditions.

Thus, to ensure economic efficiency of a building structure, it is necessary to search for optimal design solutions at conceptual design stage.

When designing buildings and structures an engineer should seek to meet various requirements for the facility under designing. Requirements may be quantitative reliability and economic efficiency, or qualitative - architectural expressiveness,

\footnotetext{
Corresponding author: vasuilkinaa@mgsu.ru
} 
maintainability, etc. Requirements to develop as reliable (durable) and at the same as economically efficient design as possible are mutually exclusive, so an engineer needs considerable experience and intuition to find the right solution and balance between them.

To successfully solve the above problem, it is necessary to offer the engineer a convenient tool for searching a design solution.

Solution search includes synthesis, analysis and selection of various options.

To solve the problem of optimal design, you can employ structural optimization approaches, which allow to achieve high results in choosing design solutions at the initial design stage, subject to proper use. The use and essence of structural optimization methods are described in detail in the publications $[3,4]$.

These operations must be performed quickly without taking much time for engineer. To do this, it is necessary to provide interactive and functional interaction between structure model and human.

Therefore, to use structural optimization methods in engineering practice, it is necessary to develop a computer-aided design system based on modern computational tools and employing information technologies.

This article illustrates possibility of applying structural optimization methods for variable design by formalizing design procedures and process of CAD tools designing and developing through the example of a structural coating plate.

\section{Methods}

Analysis of steel structures design system shows that design solution synthesis problem can be solved by using computer-aided design (CAD) systems. To do this, it is necessary to develop an appropriate methodology, including the choice of design procedures, formalization of design process, choice of CAD methods and tools.

When designing building structures, we face conflicting requirements stating that a facility under design should be as reliable as possible, i.e. it should have a large crosssection and, correspondingly, maximum metal consumption and at the same time it should be as economically efficient as possible. Accordingly, we can change one parameter and fix the other one (strength and efficiency). I.e. we get as reliable structure as possible among fixed-cost options, or we get a system with required reliability, but the cheapest, economically efficient one. Domestic design practice has developed an approach, when a structure must have required reliability - minimum permissible by standards and at the same time be economically efficient.

Appearance, shape and size of a structure under design are set by architects based on its functional purpose, construction conditions and customer desires. Design solutions that meet the requirements of architects, process engineers and manufacturers are searched for at the stage of variable or, as it is also called, conceptual design. According to P.G. Eremeev "design concept is determined by experience and integrated approach... as a result of subconscious assessment of models reliability... based on authors' individuality". [5]. I.e. design decisions are based on designer's talent, intuition and experience and it is clear that by virtue of this they cannot be many, since there is no time to work out and test every idea and model for unique and complex structures.

One of the most effective means to synthesize design solutions is evolutionary algorithms.

Genetic algorithm (GA) is one of the oldest optimization algorithms [6]. GA application in construction design began in 1986, when Goldberg and Samtoni used the GA to optimize frame structure [7]. Currently, the GA is successfully used to optimize various building structures - one-storey industrial buildings [8], to optimize the topology of steel framed 
spatial structures [9], to optimize frames topology [10], to optimize the cost of steel framework-based multi-storey buildings [11], to optimize trusses topology [4].

We will illustrate possibilities and potential benefits of using the genetic algorithm through the example of structural coating plate conceptual design.

Structural coating plates are widely used in construction of administrative and industrial structures - markets, garages, shopping malls. A feature of structural frames is their diversity and architectural expressiveness. Constructive diversity consists in possibility of changing the design scheme, type of crystal, type of elements cross-section, dimensions of crystal, plate height, type of connecting unit, method of load transferring and supports locating, etc. [12,13].

To find an optimal design solution, there is an infinite set of solutions, the elements of which are the characteristic vectors set by structure conditions (load, geometric characteristics, material characteristics), vectors constructed by their functional dependencies and a variable to identify each set.

Crystal cell size, plate height and distance between supports (Fig. 1) are taken as design variables, the range of their variation is given in Table 1.

Table 1. Variable parameters range

\begin{tabular}{|l|c|c|c|}
\hline \multicolumn{1}{|c|}{ Parameter } & Lower limit & Upper limit & Step \\
\hline Cell size $-x_{1}$ & $1.0 \mathrm{~m}$ & $4.0 \mathrm{~m}$ & $0.1 \mathrm{~m}$ \\
\hline Plate height $-x_{2}$ & $1.0 \mathrm{~m}$ & $4.0 \mathrm{~m}$ & $0.5 \mathrm{~m}$ \\
\hline Distance between supports $-x_{3}$ & $3 \mathrm{~m}$ & $9 \mathrm{~m}$ & $1 \mathrm{~m}$ \\
\hline
\end{tabular}
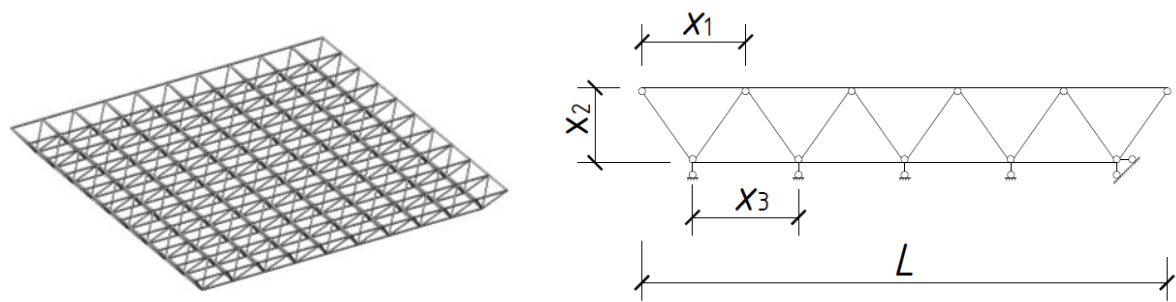

Fig. 1. Description of the geometric characteristics of a facility under study

Structure metal consumption is taken as a target function, which assumes that the structure with the least weight will be optimal.

Among all the elements of the set, there is a solution, which fulfills optimization conditions and it is as follows:

$$
C=C_{n}+C_{o} \rightarrow \min
$$

where the $C$ is the overall structure weight; $C_{n}$ is the plate weight; $C_{o}$ is the unit-forming elements weight;

Condition for choosing belt height

$$
h_{\min } \leq h_{i} \leq h_{\max }
$$

Condition of limit events non-occurrence

$$
N_{\max }=\max \left(q, H, L, a_{g, i}, h_{i}, R_{y}, A_{i}, I_{i}, a_{p, i}, l_{i}\right)
$$


where the $N_{\max }$ is the maximum force in the element; q is the load applied to the plate units; $R_{y}$ is the yield point; $A_{i}$ is the element cross-sectional area; $I_{i}$ is the inertia radius.

The condition for choosing structural plate horizontal rod length

$$
\begin{gathered}
a_{g, \min }=a_{g, 1} \\
a_{g, \min } \leq a_{g, i} \leq a_{g, \max }
\end{gathered}
$$

where the $a_{g, i}$ is that

$$
\frac{L}{a_{g, i}}=\frac{L}{a_{g, \min }}+i
$$

or

$$
\frac{l}{a_{g, i}}=\frac{L}{a_{g, \max }}-i
$$

for the $i \in\left[\frac{2}{a_{g, \max }}: \frac{2}{a_{g, \min }}\right]$

Condition of strength for stretched, of stability for compressed elements, limit deflection, limit flexibility for stretched and compressed elements is taken in accordance with regulatory requirements.

The first step in formalizing the genetic algorithm to solve the problem is to generate the first population. To do this, it is necessary to describe the individuals the population will consist of. To do this, we randomly set the variable parameters specified in Table 1 and write them in an individual vector together with non-volatile parameters.

For selection operation, elite individuals are subjected to probabilistic evaluation procedure. To do this, all the structure weight values from the elite database are summed up.

Figure 2 gives a flowchart describing the connectivity of the developed components.

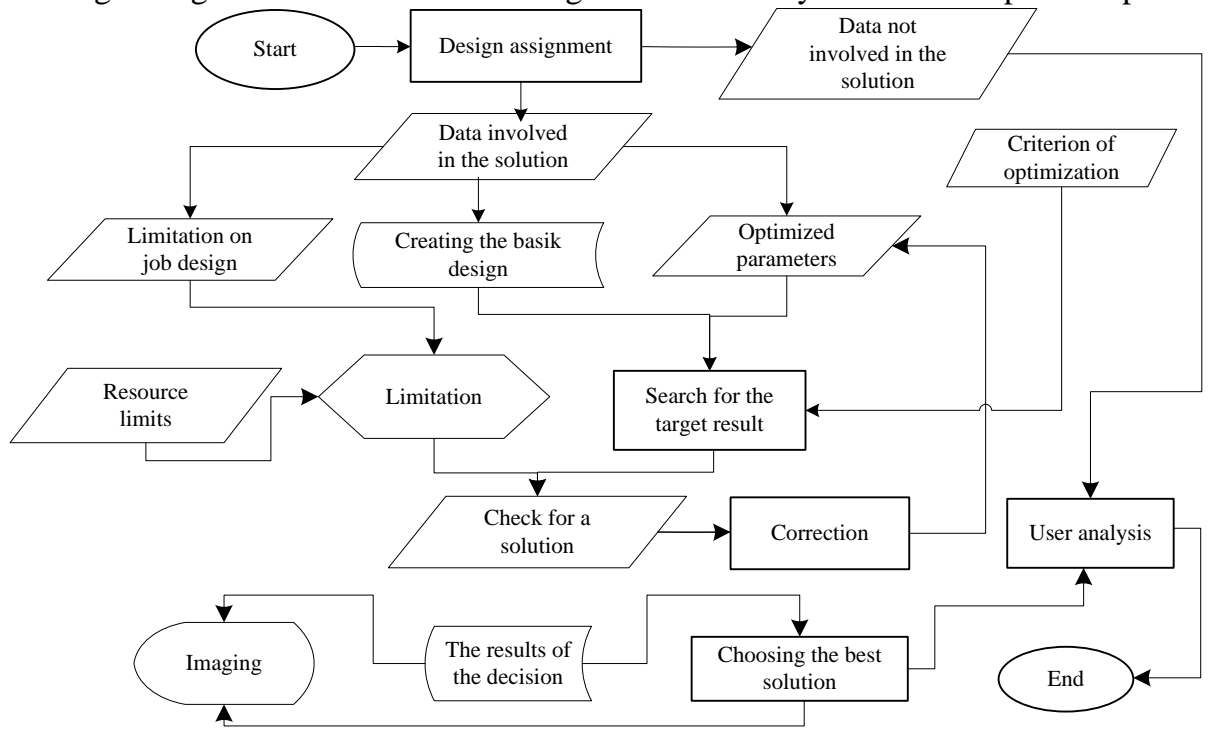

Fig. 2. Process flowchart for implementing workflow 
Since the number of parameters is rather small, the population is 50 individuals. To determine structure weight, a finite element model of the structure under study was created based on a specially developed computational tool that makes it possible to apply loads and set constraints, to perform analysis and to determine the smallest cross-section of elements for factored range meeting the strength, rigidity and stability requirements. package.

The optimal solution search problem is resolved using MATLAB 2014 software

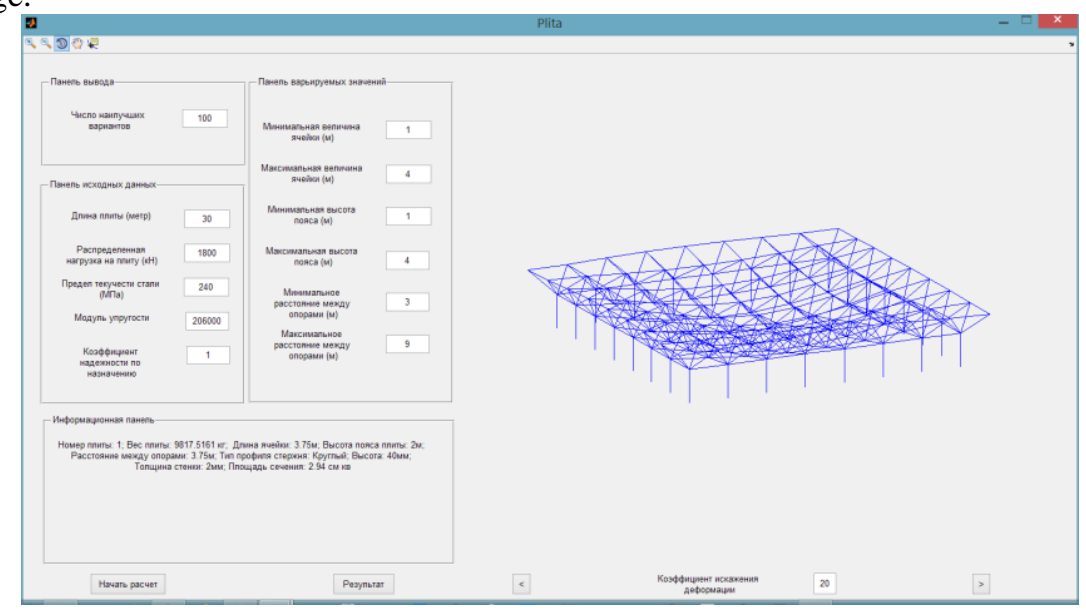

Fig. 3. Dialog box

The graphic interface (Fig. 3) is a work zone divided into several areas: data entry area; non-variable input data; variable values input panel.

Using a combination of developed user tools in the form of a FEM computational tool and optimization module based on the genetic algorithm makes up a computer-aided design system for synthesis of design solutions at the conceptual design stage and allows to choose an optimal solution for structural plate coating.

\section{Study results}

The most effective way to interact with the model in real time is feedback. Information visual representation in the dialog box, as in Fig.3 is the fastest and visual technique for comparison of variants of all types of structures with geometric variables.

When working with the program, we obtained various topologies of the structural plate. As a result of calculation with specified values, the system synthesized 800,000 variants for structural frame topology, 100 best variants of which were selected in order of structure increasing weight. (Fig. 4).

The first nine variants of synthesized structural plate design solutions are given below
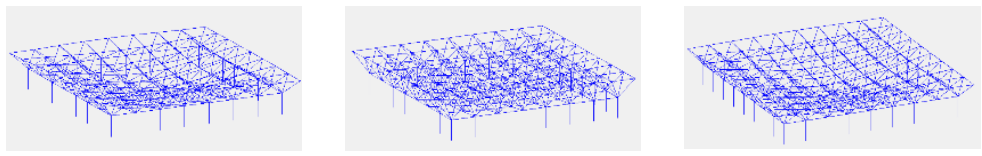

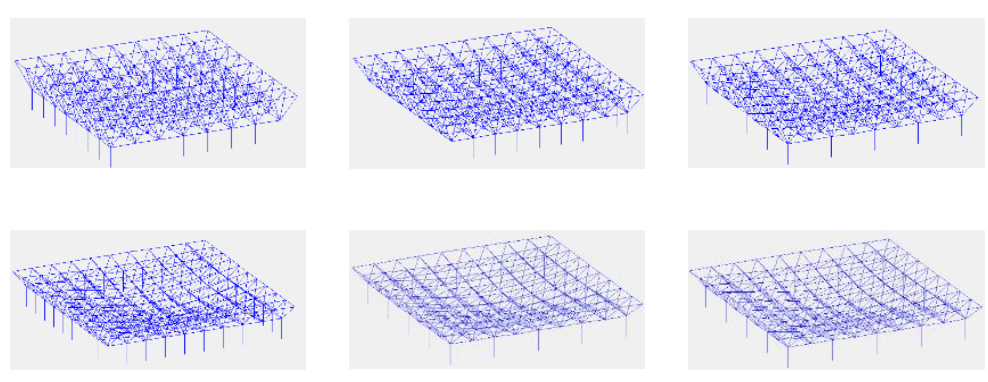

Fig. 4. Examples of synthesized solutions

Calculation was carried out for 42 minutes, which given 7-times speed advantage as compared with direct and iterative calculation methods. There is no need to manually rebuild finite element model, which greatly simplifies designer's work when searching for a solution.

The selected topology can be taken as a structure main run-time version and subjected to a full check at the "design" stage.

\section{Discussions}

In the end, a genetic algorithm-based conceptual design tool has been developed, which synthesizes a large number of design solutions for steel structures in dialog mode with user. Engineer gets visualized solutions among which he can choose an optimal one according to the accepted optimization criterion or as close as possible to the optimal one, based on their specific design conditions.

Possibility of applying structural optimization methods for synthesis and analysis of design solutions is demonstrated by CAD tools development. Introduction of these technologies in construction design is one of the directions for cyber-physical building systems evolution [14].

Structural optimization is a methodology that helps to solve the set problems, to meet the needs of engineers and to guide solutions search in variable design [15].

This work was financially supported by Ministry of Science and Higher Education of the Russian Federation (\#NSh-3492.2018.8).

\section{References}

1. A.Ginzburg, A.Vasilkin, Vestnik MGSU, 6, 52-62 (2014)

2. Ya.Likhtarnikov, Variantnoe proektirovanie $i$ optimizatsiya stal'nykh konstruktsii. M.: Stroiizdat. (1979)

3. A.Perel'muter, Vestnik Tomskogo gosudarstvennogo arkhitekturno-stroitel'nogo universiteta, 2, 70-106 (2016)

4. C.Mueller, J.Ochsendorf, Automation in Construction, 52, 70-82 (2015)

5. P.Eremeev, Sovremennye stal'nye konstruktsii bol'sheproletnykh pokrytii unikal'nykh zdanii i sooruzhenii. p. 336 (2009)

6. Xin-She Yang, G. Bekdaş, S. M. Nigdeli. Metaheuristics and Optimization in Civil Engineering. Springer (2018). DOI 10.1007/978-3-319-26245-1

7. D. Goldberg, M.Samtani, Proceedings of Ninth Conference on Electronic Computation. ASCE, New York, NY, pp. 471-482 (1986) 
8. S.Kravanja, Goran G. Turkalj, S. T. Šilih, Journal of Constructional Steel Research 81:86-103.DOI: 10.1016/j.jcsr.2012.11.008.

9. K.Konstantinos, D. Tsavdaridis, V.Toropov High-rise Buildings \& Steel Components. Jordan Journal of Civil Engineering, 9, No. 3, (2015).

10. A.Kaveh, M.H. Ghafari. International journal of optimization in civil engineering Int. J. Optim. Civil Eng, 5(4), 479-492 (2015)

11. A. R. Kulkarni. International Journal of Engineering Research \& Technology (IJERT). 5, 07, 123-127, (2016)

12. A. Nikityuk, A. Moskovkina, I. Zueva Vestnik PNIPU. Stroitel'stvo i Arkhitektura,1, 99-104 (2011)

13. R. Khisamov, Raschet i konstruirovanie strukturnykh pokrytii. Kiev,p.48 (1981)

14. A. Volkov, Promyshlennoe i grazhdanskoe stroitel'stvo,9, 4-7, (2017)

15. A. Vasilkin. E3S Web of Conferences (HRC 2017) 